\title{
Ameloblastic carcinoma
}

INSERM

\section{Source}

INSERM. (1999). Orphanet: an online rare disease and orphan drug data base.

Ameloblastic carcinoma. ORPHA:314422

Ameloblastic carcinoma is a rare odontogenic tumor characterized by aggressive clinical course and local destruction, occurring in mandible more often than in maxilla. The most common symptom is a rapidly progressing painful swelling, but it may present as a benign cystic lesion or as a large, rapidly growing mass with ulceration, bone resorption and teeth mobility, as well. The tumor may metastasize, most commonly to the cervical lymph nodes and the lungs. 